\title{
PENINGKATAN PENGETAHUAN DAN KETERAMPILAN TERKAIT PENCEGAHAN DAN PENGELOLAAN KASUS HIPERTENSI DI KELURAHAN TANJUNG HARAPAN KOTABUMI
}

DOI: https://doi.org/10.33024/jkpm.v4i5.4933

\author{
Derista Hartati ${ }^{1}$, Rika yulendasari ${ }^{2^{*}}$ \\ ${ }^{1}$ Mahasiswa Program Studi Keperawatan \\ ${ }^{2}$ Dosen Universitas Malahayati \\ Disubmit: 27 Agustus 2021 Diterima: 03 September 2021 \\ Diterbitkan: 03 Oktober 2021
}

Email korespondensi: rikajeng@gmail.com

\begin{abstract}
ABSTRAK
Prevalensi hipertensi mengalami peningkatan dari tahun 2013 yaitu sebanyak 25,8\% menjadi 34,1\% pada tahun 2018. Dari seluruh prevalensi hipertensi sebesar $34,1 \%$ pada tahun 2018 , hanya sebesar $8,8 \%$ pasien yang terdiagnosis hipertensi dengan 13,3\% pasien tidak minum obat serta 32,3\% pasien tidak rutin minum obat. Tujuan setelah dilakukan penyuluhan diharapkan masyarakat dapat mengetahui pencegahan dan pengelolaan hipertensi khususnya masyarakat di Kelurahan Tanjung Harapan Kotabumi. Kegiatan dilakukan dengan penyuluhan mengenai hipertensi menggunakan media pamflet dan leaflet. Setelah dilakukan tanya jawab dua arah dengan masyarakat Kelurahan Tanjung Harapan Kotabumi terdapat peningkatan pengetahuan mengenai pencegahan dan pengelolaan hipertensi.
\end{abstract}

Kata Kunci: Hipertensi, Pencegahan, Pengelolaan

\begin{abstract}
The prevalence of hypertension has increased from 2013 which was $25.8 \%$ to $34.1 \%$ in 2018 . Of the total hypertension prevalence of $34.1 \%$ in 2018 , only $8.8 \%$ of patients were diagnosed with hypertension with $13.3 \%$ patients do not take medication and $32.3 \%$ of patients do not take medication regularly. The goal after the counseling is expected that the community can know the prevention and management of hypertension, especially the community in Tanjung Harapan Village, Kotabumi. The activity was carried out with counseling about hypertension using pamphlets and leaflets as media. After a two-way question and answer session with the people of Tanjung Harapan Kotabumi Village, there was an increase in knowledge about the prevention and management of hypertension.
\end{abstract}

Keywords: Hypertension, Prevention, Management 


\section{PENDAHULUAN}

Hipertensi merupakan keadaan dimana tekanan darah seseorang meningkat. Hipertensi ditandai dengan meningkatnya tekanan sistolik $\geq 160$ $\mathrm{mmHg}$ dan atau tekanan diastolik $\geq 95 \mathrm{mmHg}$ (Tjokronegoro, 2001). Terapi untuk hipertensi pun tergantung dari keparahan gejala yang diderita. Prevalensi hipertensi di Indonesia pada usia > 18 tahun di Indonesia yang didapat melalui jawaban pernah didiagnosa tenaga kesehatan sebesar 9,4 persen, sedangkan yang pernah didiagnosis tenaga kesehatan atau sedang minum obat hipertensi sendiri sebesar 9,5 persen. Hadi, terdapat 0,1 persen penduduk yang minum obnat sendiri, meskipun tidak pernah didiagnosis hipertensi oleh nakes (Riskesdas, 2013).

Hipertensi dapat menimbulkan morbiditas atau mortalitas dini, yang meningkat saat tekanan darah sistolik dan diastolik meningkat. Peningkatan tekanan darah yang berkepanjangan dapat merusak pembuluh darah di organ target seperti jantung, ginjal, otak dan mata (Smeltzer, 2017). Peningkatan tekanan darah disebabkan oleh banyak faktor, diantaranya jenis kelamin, latihan fisik, makanan, stimulan (zat-zat yang mempercepat fungsi tubuh), stress emosional (marah, takut, dan aktivitas seksual), kondisi penyakit (arteriosklerosis), hereditas, nyeri, obesitas, usia, serta kondisi pembuluh darah (Noorhidayah et al., 2020)

Wanita lansia yang memasuki usia menopause dapat mengalami hipertensi dipengaruhi oleh faktor hormonal serta beberapa faktor lain yaitu faktor keturunan, faktor lingkungan, usia, stres, gaya hidup, garam, merokok, kurang olahraga atau aktifitas, dan pola makan. Bagi kebanyakan perempuan, gejala premenopause akan muncul pada rentang waktu usia 40 tahun. Wanita yang mengalami masa premenopause akan mengalami gejala puncak (klimakrterium) dan mempunyai masa transisi atau masa peralihan. Fase ini disebut estrogen dan testosteron yang mengakibatkan disfungsi endothelial dan menambah BMI yang menyebabkan kenaikan pada aktivasi saraf simpatetik. Aktivasi saraf simpatetik ini akan mengeluarkan stimulan renin dan angiotensin II. kenaikan angiotensin and endhotelin dapat menyebabkan stres oksidatif yang berujung pada hipertensi atau darah tinggi (Daherba, 2017).

Adapun penelitian yang terkait dengan hipertensi yaitu Yuliana Fajarsari Hubungan Tingkat Pengetahuan Tentang Hipertensi Dengan Perilaku Pencegahan Terjadinya Hipertensi Pada Jemaah Haji Di Wilayah Kerja Puskesmas Kotagede I Yogyakarta. Hasil penelitian ini menunjukkan tingkat pengetahuan tentang hipertensi dan perilaku pencegahan terjadinya hipertensi berada pada kategori baik. Namun masih ada sub variabel yang kurang. Diharapkan bagi perawat Puskesmas Kotagede I Yogyakarta hendaknya lebih meningkatkan pendampingan, pemberian edukasi kesehatan, dan penyebaran informasi kesehatan kepada jemaah haji saat ada kegiatan pertemuan seperti kontrol ke puskesmas dan kegiatan posbindu agar kesehatan jemaah haji tetap terkendali dengan baik dan melibatkan tokoh masyarakat dalam intervensi kepada jemaah haji.

Hipertensi menjadi salah satu penyakit yang prevalensinya semakin meningkat di Indonesia. Berdasarkan data dari Riskesdas Litbang Depkes (2013), prevalensi hipertensi di Indonesia sebanyak 25,8\%. Pada tahun 2018 perkiraan jumlah kasus hipertensi di Indonesia sebanyak 34,1\% yaitu 63.309.620 jiwa dengan jumlah kematian sebanyak 427.218 jiwa. Hipertensi terbanyak terdapat pada umur 55-64 tahun $(55,2 \%)$, lalu disusul umur 45-54 tahun (45,3\%), dan kelompok umur $31-44$ tahun $(31,6 \%)$ 
(Riskesdas Kementerian Kesehatan RI, 2018). Dari seluruh prevalensi hipertensi sebesar $34,1 \%$ pada tahun 2018 , hanya sebesar $8,8 \%$ pasien yang terdiagnosis hipertensi dengan $13,3 \%$ pasien tidak minum obat serta $32,3 \%$ pasien tidak rutin minum obat (P2PTM Kemenkes RI, 2019).

Tidak terdiagnosisnya banyak penduduk yang menderita hipertensi bisa disebabkan oleh kurangnya akses kesehatan di daerah tersebut dan kurangnya perhatian masyarakat pada penyakit hipertensi. Padahal hipertensi merupakan faktor risiko berbagai penyakit,termasuk kerusakan organ seperti gagal ginjal, penyakit kardiovaskuler, hingga yang fatal adalah stroke sampai dengan kematian. Data dari Puskesmas Kotabumi II menunjukkan bahwa terdapat 218 kunjungan pasien hipertensi dalam kurun waktu Januari hingga Agustus 2021. Sedangkan, total keseluruhan kunjungan hipertensi di Kecamatan Kotabumi Selatan pada periode waktu yang sama yaitu sejumlah 1052 .

Berdasarkan hal tersebut, penulis tertarik melakukan penelitian mengenai Peningkatan Pengetahuan dan Ketrampilan terkait Pencegahan Kasus Hipertensi di Kelurahan Tanjung Harapan Kotabumi.

\section{MASALAH}

Alasan kami memilih tempat kegiatan karena di kelurahan Tanjung Harapan merupakan salah satu kelurahan yang tertinggi angka kunjungan ke Puskesmas Kotabumi II dengan penyakit hipertensi. Selain itu masyarakatnya masih belum mengetahui tentang penyakit hipertensi dan cara pencegahannya. Tujuan khusus dari penelitian ini adalah masyarakat mengetahui tentang penyakit hipertensi dan mengetahui pencegahannya.

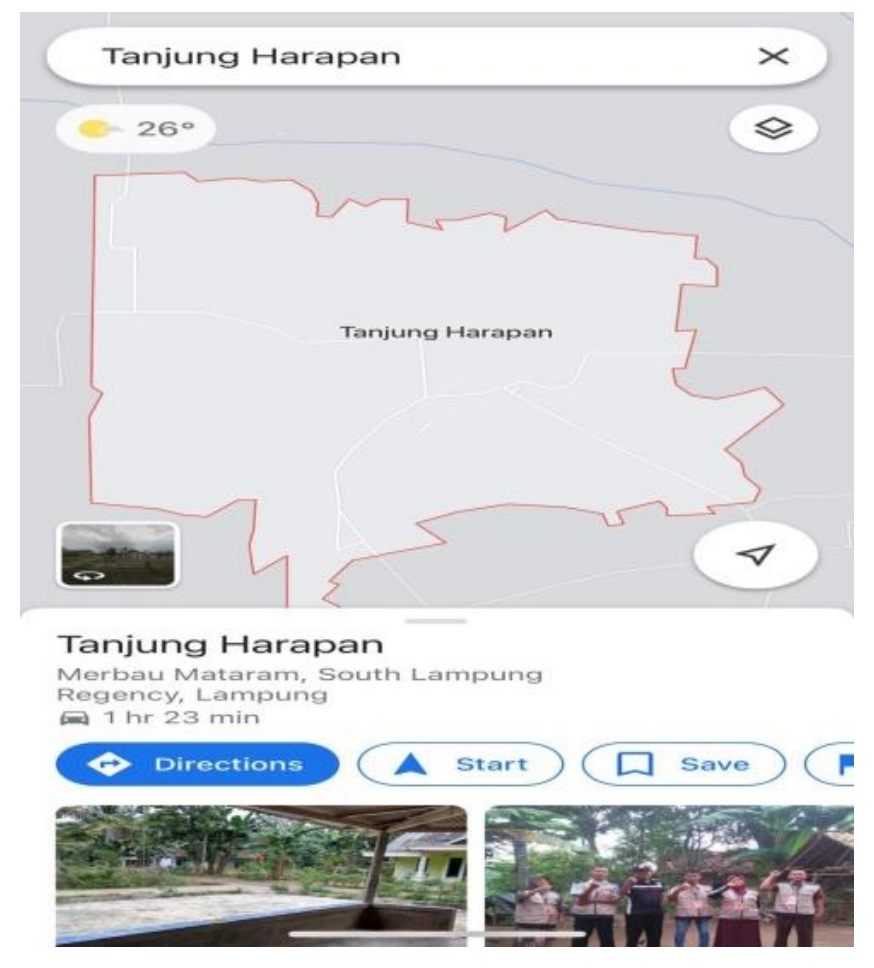

Gambar 2.1 Peta Lokasi Kegiatan Pengabdian Masyarakat. 


\section{METODE}

a. Tahap Persiapan

Tahap persiapan dari kegiatan ini adalah pembuatan leaflet yang merupakan media untuk menjelaskan kepada masyakat agar lebih mudah dipahami. Kemudian dilakukan koordinasi dengan lurah setempat untuk melaksanakan penyuluhan kepada masyarakat kelurahan Tanjung Harapan di balai desa/aula kantor kelurahan.

b. Tahap Pelaksanaan

Tahap Pelaksanaan dari kegiatan ini adalah dengan cara kunjungan rumah terhadap masyarakat yg menderita penyakit hipertensi dengan sampel sebanyak 18 orang.

c. Evaluasi

i. Struktur

Melakukan penyuluhan di balai desa/aula kelurahan setempat dengan dibagi menjadi tiga sesi guna mencegah kerumunan. Peserta yang ikut berpartisipasi berdasarkan data dari Puskesmas Kotabumi II yaitu masyarakat yang menderita hipertensi, kemudian penyuluhan dilaksanakan dengan diawali penjelasan mengenai maksud dan tujuan kunjungan tersebut.

ii. Proses

Pelaksanaan kegiatan dari tanggal 20 - 22 Agustus 2021.

\section{HASIL DAN PEMBAHASAN}

Pelaksanaan kegiatan penyuluhan hipertensi kepada masyarakat kelurahan Tanjung Harapan berjalan dengan baik. Penyuluhan dilaksanakan di Aula Kantor Kelurahan Tanjung Harapan Kotabumi, Lampung Utara pada tanggal 20-22 Agustus 2021. Metode yang digunakan adalah ceramah dengan presentasimenggunakan pamflet dan leaflet, kemudian dilakukan sesi tanya jawab dua arah untuk mengetahui apakah peserta sudah mengerti mengenai materi penyuluhan yang telah diberikan. Berikut gambar pelaksanaan kegiatan:

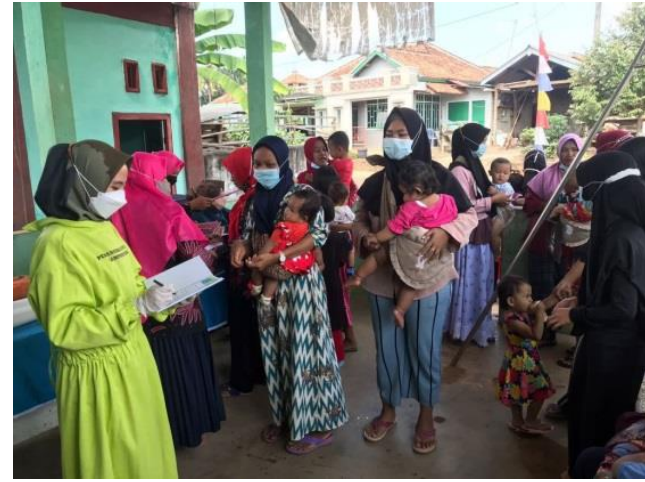

Gambar 2.2 Kegiatan penyuluhan

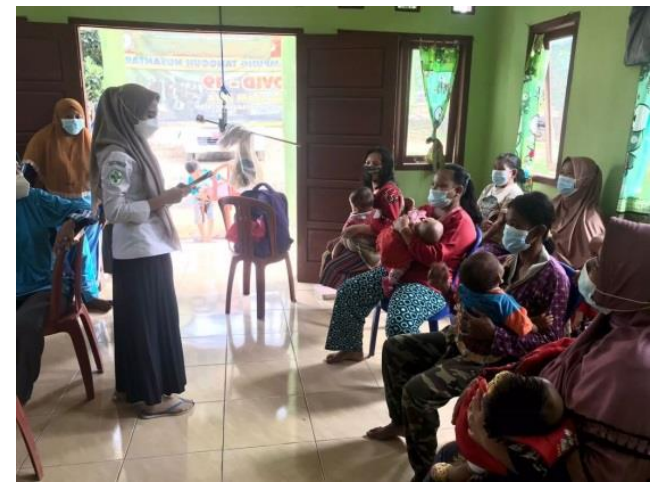

Gambar 2.3 Kegiatan penyuluhan 


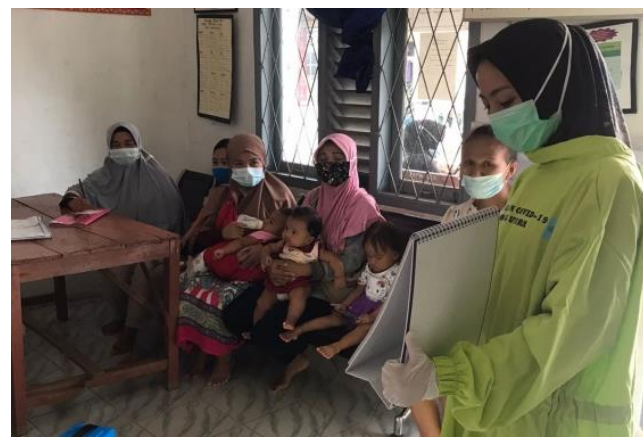

Gambar 2.4 Kegiatan penyuluhan

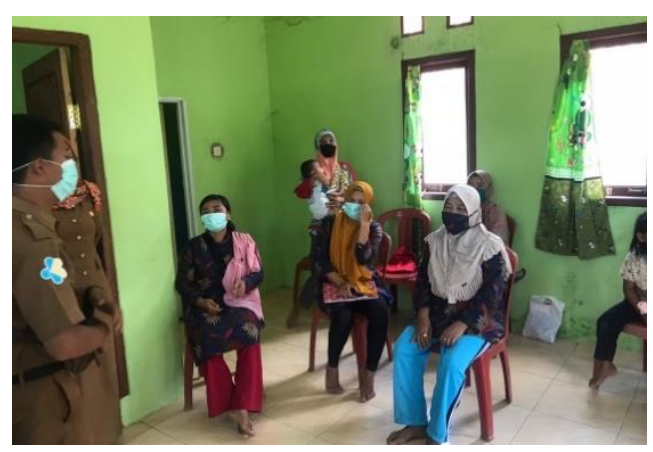

Gambar 2.5 Kegiatan penyuluhan

\section{KESIMPULAN}

Penyakit hipertensi merupakan penyakit yang dapat dikontrol dengan minum obat rutin dan memperbaiki pola hidup, akan tetapi penyakit hipertensi dapat menjadi salah satu penyakit berbahaya dan menyebabkan komplikasi diantaranya, stroke, gagal ginjal, penyakit jantung dan lainnya. Oleh karena itu, penting dilakukannya pendidikan kesehatan terhadap masyarakat guna menurunkan angka kejadian hipertensi dan dapat melakukan pencegahan terhadap penyakit tersebut.

\section{DAFTAR PUSTAKA}

Balitbang Kemenkes RI. (2013). Riset Kesehatan Dasar; RISKESDAS. Jakarta: Balitbang Kemenkes RI

Deherba. (2017). Hubungan Hipertensi dan Menopause. diakses dari https: / / www.deherba.com/h ipertensi-danmenopause.html

Noorhidayah, Setiandari, E., \& Octaviana, L. (2020). Hubungan Tingkat Pengetahuan dan Sikap Masyarakat dengan Upaya Pencegahan Penyakit Hipertensi. Jurnal IImiah IImu Kesehatan, 6(1), 21-25. https://doi.org/https://doi.org/10.33485/wk-jiik

P2PTM Kemenkes RI. (2019). Hari Hipertensi Dunia 2019 : “Know Your Number, Kendalikan Tekanan Darahmu dengan CERDIK."

Riskesdas. (2013). Riset Kesehatan Dasar Tahun 2013. Kemenkes RI.

Riskesdas Kementerian Kesehatan RI. (2018). Hasil Utama Riset Kesehatan Dasar (RISKESDAS) (Vol. 44, Issue 8). https://doi.org/10.1088/17518113/44/8/085201

Smeltzer, S. C. (2017). Buku Ajar Keperawatan Medikal Bedah Brunner \& Suddarth. Jakarta : EGC.

Tjokronegoro dan H. Utama. Buku Ajar Ilmu Penyakit Dalam II. In: E. Susalit, E.J.Kapojos, dan H.R. Lubis ed. Hipertensi Primer. Jakarta: Gaya Baru; 2001. p:453-456.

Yuliana Fajarsari. 2020. Hubungan Tingkat Pengetahuan Tentang Hipertensi Dengan Perilaku Pencegahan Terjadinya Hipertensi Pada Jemaah Haji Di Wilayah Kerja Puskesmas Kotagede I Yogyakarta. Skripsi. Yogyakarta: Politeknik Kesehatan Kementerian Kesehatan Yogyakarta.

Yuli Yantina, Ajeng Saputri. (2018). Pengaruh Senam Lansia Terhadap Tekanan Darah Pada Wanita Lansia Dengan Hipertensi Di Wilayah Kerja Puskesmas Banjarsari Metro Utara Tahun 2018. Jurnal Farmasi Malahayati Vol 2 No 1. 